\title{
Effects of Prenatal Exposure to the Dutch Famine on Adult Disease in Later Life: An Overview
}

\author{
Tessa J. Roseboom', Jan H.P. van der Meulen², Anita C.J. Ravelli ${ }^{3}$, Clive Osmond ${ }^{4}$, David J.P. Barker ${ }^{5}$ \\ and Otto P. Bleker ${ }^{6}$ \\ ' Tessa J. Roseboom: Dept. Clinical Epidemiology and Biostatistics, Academic Medical Center, Amsterdam, the Netherlands \\ ${ }^{2} J a n$ van der Meulen: Health Services Research Unit, London School of Hygiene and Tropical Medicine, London, UK \\ ${ }^{3}$ Anita Ravelli: Department of Medical Informatics, Academic Medical Center, Amsterdam, the Netherlands \\ ${ }^{4}$ Clive Osmond and David Barker: MRC Environmental Epidemiology Unit, University of Southampton, Southampton, UK \\ ${ }^{5}$ Otto Bleker: Department of Obstetrics and Gynecology, Academic Medical Center, Amsterdam, the Netherlands.
}

\begin{abstract}
Deople who were small at birth have been shown to have an increased risk of CHD and chronic bronchitis in later life. These findings have led to the fetal origins hypothesis that proposes that the fetus adapts to a limited supply of nutrients, and in doing so it permanently alters its physiology and metabolism, which could increase its risk of disease in later life. The Dutch famine though a historical disaster - provides a unique opportunity to study effects of undernutrition during gestation in humans. People who had been exposed to famine in late or mid gestation had reduced glucose tolerance. Whereas people exposed to famine in early gestation had a more atherogenic lipid profile, somewhat higher fibrinogen concentrations and reduced plasma concentrations of factor $\mathrm{VII}$, a higher $\mathrm{BMI}$ and they appeared to have a higher risk of $\mathrm{CHD}$. Though the latter was based on small numbers, as could be expected from the relatively young age of the cohort. Nevertheless, this is the first evidence in humans that maternal undernutrition during gestation is linked with the risk of $\mathrm{CHD}$ in later life. Our findings broadly support the hypothesis that chronic diseases originate through adaptations made by the fetus in response to undernutrition. The long-term effects of intrauterine undernutrition, however, depend upon its timing during gestation and on the tissues and systems undergoing critical periods of development at that time. Furthermore, our findings suggest that maternal malnutrition during gestation may permanently affect adult health without affecting the size of the baby at birth. This gives the fetal origins hypothesis a new dimension. It may imply that adaptations that enable the fetus to continue to grow may nevertheless have adverse consequences for health in later life. CHD may be viewed as the price paid for successful adaptations to an adverse intra-uterine environment. It also implies that the long-term consequences of improved nutrition of pregnant women will be underestimated if these are solely based on the size of the baby at birth. We need to know more about what an adequate diet for pregnant women might be. In general, women are especially receptive to advice about diet and lifestyle before and during a pregnancy. This should be exploited to improve the health of future generations.
\end{abstract}

Chronic degenerative diseases are the main public health problem in most Western countries. Cardiovascular disease, respiratory disease and cancer have become the commonest causes of death and account for three quarters of mortality at adult age (Murray \& Lopez, 1994). A growing body of evidence suggests that these diseases originate in the womb.
People who were small at birth have been shown to have an increased risk of CHD and chronic bronchitis in later life (Barker, 1998). Cancer, however, has been linked to increased birth weight (Michels et al., 1996). The link between size at birth and health in later life is thought to reflect programming. This term is used to describe the process by which a stimulus or insult during critical periods of growth and development has lasting effects on the structure or function of tissues and body systems. Programming occurs because the tissues and systems of the body go through critical, often brief, periods of growth and development during fetal life and infancy. Failure of development during these periods as a result of adverse environmental influences changes the body's structure and function permanently.

The associations between small size at birth and CHD later in life have extensively been replicated in studies in several European countries, but also in the US and in India (Eriksson et al., 1999; Forsen et al., 1999; Huxley et al., 2000; Leon et al., 1998; Lithell et al., 1996; Osmond et al., 1993; Rich-Edwards et al., 1997). They extend across the normal range of size at birth and depend on small size for gestational age rather than on prematurity (Eriksson et al., 1999; Leon et al., 1998). A study in Finland showed that the path of growth in childhood modifies the risk of CHD associated with small size at birth. Death rates from CHD were highest among men who were thin at birth but had accelerated weight gain in childhood (Eriksson et al., 1999). The effect size, a more than five fold increase in mortality among men who were thin at birth and overweight at age 11 compared to men with a high ponderal index at birth and lean in childhood, is among the largest found in cardiovascular epidemiology.

These findings have led to the fetal origins hypothesis that proposes that the fetus adapts to a limited supply of

Address for correspondence: Tessa J Roseboom, Dept. Clinical Epidemiology and Biostatistics, Academic Medical Center, Amsterdam, the Netherlands.Email:t.j.roseboom@amc.uva.nl 
nutrients, and in doing so it permanently alters its physiology and metabolism, which could increase its risk of disease in later life (Barker, 1998). The Dutch famine - though a historical disaster — provides a unique opportunity to study effects of undernutrition during gestation in humans. Famine has seldom, if ever, struck where extensive, reliable and valid data allow the long-term effects to be studied. Moreover, the famine occurred in a previously well-nourished population, it was sharply circumscribed in both time and place, and, the type and degree of nutritional deprivation during the famine were known with a precision unequalled in any large human population before or since. All these characteristics enable that the Dutch famine can be considered as a unique 'experiment of history' to test the fetal origins hypothesis. The fetus becomes undernourished when its demand for nutrients, which largely depends on its rate of growth, exceeds its supply. Nutrient supply to the fetus depends on maternal nutritional state and the fetal supply line. The famine affected maternal nutrition, but possible not the fetal supply line. So the famine enables us to assess the contribution of maternal dietary intake and to a lesser extent maternal body composition to fetal programming of adult disease.

\section{The Dutch Famine 1944 - 1945}

After weeks of heavy fighting following the invasion of France on the 6th of June 1944, the Allied forces finally broke through German lines. With lightning speed the Allied troops took possession of much of France, Luxembourg and Belgium. By the 4th of September 1944 the Allies had the strategic city of Antwerp in their hands, and on the 14th they entered the Netherlands. Everyone in the Netherlands expected that the German occupation would soon be over. The advance went so quickly that the commanders of the Allied forces also thought it would be only a matter of days before the Germans would surrender. But the advance of the Allies to the north of the Netherlands came to a halt when attempts to get control of the bridge across the river Rhine at Arnhem (operation 'Market Garden') failed.

In order to support the Allied offensive, the Dutch government in exile had called for a strike of the Dutch railways. As a reprisal, the Germans banned all food transport. This embargo on food transport was lifted in early November 1944, when food transport across water was permitted again. By then, it had become impossible to bring in food from the rural east to the urban west of the Netherlands because most canals and waterways were frozen due to the extremely severe winter of 1944 - 1945, which had started unusually early. Consequently, food stocks in the urban west of the Netherlands ran out rapidly.

As a result, the official daily rations for the general adult population - which had decreased gradually from about 1800 calories in December 1943, to 1400 calories in October 1944 - fell abruptly to below 1000 calories in late November 1944. At the height of the famine from December 1944 to April 1945, the official daily rations varied between 400 and 800 calories. Children younger than 1 year were relatively protected, because their official daily rations never fell below 1000 calories, and the specific nutri- ent components were always above the standards used by the Oxford Nutritional Survey (Burger et al., 1948). Pregnant and lactating women were entitled to an extra amount of food, but at the peak of the famine these extra supplies could not be provided any more. In addition to the official rations, food came from church organisations, central kitchens, the black market and foraging trips to the countryside (Trienekens, 1985). After the liberation of the Netherlands in early May 1945, the food situation improved swiftly. In June 1945, the rations had risen to more than 2000 calories (Burger et al., 1948).

There was a serious shortage of fuel during the war which caused a gradual decrease and finally a complete shutting down of the production of gas and electricity, and in several places even the water supply had to be cut off, while the authorities were unable to provide fuel for stoves and furnaces in homes. Throughout the winter of $1944-1945$ the population had to live without light, without gas, without heat, laundries ceased operating, soap for personal use was unobtainable, and adequate clothing and shoes were lacking in most families. In hospitals, there was serious overcrowding as well as lack of medicines. Above all, hunger dominated all misery.

The famine had a profound effect on the general health of the population. In Amsterdam, the mortality rate in 1945 was more than double compared to 1939, and it is likely that most of this increase in mortality was attributable to malnutrition (Banning, 1948). But, even during this disastrous famine women conceived and gave birth to babies, and it is in these babies that the effects of maternal malnutrition during different periods of gestation on health in adult life can be studied.

\section{The Dutch Famine Birth Cohort Study}

We studied people who were born around the time of the Dutch famine in a university hospital, in Amsterdam, the Netherlands. All singletons born alive between 1 November 1943 and 28 February 1947 in the Wilhelmina Gasthuis in Amsterdam, were candidates to be included in the Dutch famine birth cohort. We excluded babies whose main medical records were missing, and those with a gestational age at birth of less than 259 days. In all, 2414 babies were included. The Bevolkingsregister of Amsterdam traced 2155 (89\%) of the 2414 babies. Of these, 265 had died, 199 had emigrated from the Netherlands and 164 did not allow the population registry to give us their address. We obtained the current addresses of 1527 people and asked 1018 people who lived in or close to Amsterdam to be interviewed, 912 of them agreed to be interviewed about their medical history and current health. Of these, 741 attended the clinic to undergo more detailed measurements. Mean birth weights among the 912 who were visited at home or the 741 who attended the clinic did not differ from the rest of the 2414 babies (difference adjusted for exposure to famine $12 \mathrm{~g}, p=0.5$, and $22 \mathrm{~g}, p=0.3$, respectively).

We considered a baby to be exposed to famine in utero if the average daily ration during any 13 week period of gestation was below 1000 calories. We used three periods of 16 weeks to distinguish between babies exposed during late gestation (born between 7 January and 28 April 1945), 
mid gestation (29 April to 18 August 1945) and early gestation (19 August to 8 December 1945). We compared the exposed babies with babies born before or conceived after the famine period, whom we grouped as unexposed.

\section{Findings}

Of the 2414 babies who were included, 307 were exposed in late gestation, 297 exposed in mid gestation and 217 in early gestation. People conceived after the famine had the lowest mortality up to age $50(7.2 \%)$. Mortality was higher in those exposed to famine in early gestation $(11.5 \%)$ and mid gestation (11.2\%). Mortality was highest in those exposed to famine in late gestation $(14.6 \%)$ and those born before the famine $(15.2 \%)$. The differences in mortality were caused by effects of famine on mortality in the first year of life, and these deaths were mainly related to nutrition and infections (Roseboom et al., 2001). There were no differences in either overall or cause-specific mortality in adulthood between the exposure groups.

Women who were exposed to famine in late pregnancy were slightly older than women in the other exposure groups and a higher proportion of them was married (Table 1). Women exposed to famine in late pregnancy did not gain any weight in the third trimester, whereas women exposed in mid and early pregnancy gained more weight than unexposed mothers did due to the immediate provision of food after the war. Consequently women exposed in late pregnancy weighed less at their last prenatal visit.

Exposure to famine during gestation had an effect on the sex ratio of liveborn babies. The percentage of boys born alive was lower, especially after exposure in late gestation. Babies exposed to famine in late gestation were lighter, shorter, and thinner with smaller heads and placentas than unexposed babies. Babies exposed to famine in mid gestation were lighter, shorter, and had smaller heads than unexposed ones.
Children who were exposed to famine in early gestation were heavier and longer at birth.

\section{Adult Disease}

People who had been exposed to famine in late or mid gestation had reduced glucose tolerance, shown by increased 2 hr plasma glucose concentrations (Ravelli et al., 1998). We also found that those who were light at birth had increased $2 \mathrm{hr}$ plasma glucose concentrations, but the effects of exposure to famine on glucose tolerance were larger than could be explained by the small famine-related reduction in birth weight. We found that people exposed to famine in early gestation had a more atherogenic lipid profile (Roseboom et al., 2000), somewhat higher fibrinogen concentrations and reduced plasma concentrations of factor VII (Roseboom et al., 2000), a higher BMI (Ravelli et al., 1999) and they appeared to have a higher risk of CHD (Roseboom et al., 2000). Though the latter was based on small numbers, as could be expected from the relatively young age of the cohort. Nevertheless, this is the first evidence in humans that maternal undernutrition during gestation is linked with the risk of CHD in later life. In addition, people who had been exposed to famine in early gestation more often rated their health as poor. This indicates that they are not only less healthy in terms of objective measures of health, but that they also feel less healthy. Because the famine ended abruptly, the women who conceived during the famine (and whose fetuses were thus undernourished in early gestation) were well nourished in later pregnancy, which may have contributed to the above average birth weight of their babies. The transition from nutritional deprivation in early gestation to nutritional adequacy later on may have led to metabolic conflicts resulting in disease in later life.

Although we found that people who had been small at birth had high blood pressures in later life we could not

Table 1

Maternal, and Infant Characteristics According to Timing of Prenatal Exposure to the Dutch Famine. (* Geometric Mean and SD)

\begin{tabular}{|c|c|c|c|c|c|c|c|}
\hline & \multicolumn{6}{|c|}{ Exposure to famine in } & \multirow[b]{2}{*}{$n$} \\
\hline & $\begin{array}{l}\text { born } \\
\text { before }\end{array}$ & $\begin{array}{c}\text { late } \\
\text { gestation }\end{array}$ & $\begin{array}{c}\text { mid } \\
\text { gestation }\end{array}$ & $\begin{array}{c}\text { early } \\
\text { gestation }\end{array}$ & $\begin{array}{l}\text { conceived } \\
\text { after }\end{array}$ & all $(S D)$ & \\
\hline proportion of men & $50 \%$ & $47 \%$ & $42 \%$ & $44 \%$ & $52 \%$ & $48 \%$ & 2414 \\
\hline \multicolumn{8}{|l|}{ Maternal characteristics } \\
\hline Weight last prenatal visit $(\mathrm{kg})$ & 66.7 & $61.8^{\dagger}$ & $63.5^{\dagger}$ & 67.9 & 69.1 & $66.6(8.7)$ & 2133 \\
\hline Weight gain 3rd trimester $(\mathrm{kg})$ & 3.2 & $0.0^{\dagger}$ & $4.9^{\dagger}$ & $5.7^{\dagger}$ & 4.3 & $3.5(3.2)$ & 1682 \\
\hline Primiparous & $40 \%$ & $30 \%$ & $37 \%$ & $39 \%$ & $39 \%$ & $38 \%$ & 2414 \\
\hline Age (yrs) & 29 & 30 & 28 & 28 & 28 & $28(6.4)$ & 2414 \\
\hline Not married & 13.2 & 9.8 & 20.2 & 25.8 & 16.3 & 15.8 & 2414 \\
\hline \multicolumn{8}{|l|}{ Infant characteristics } \\
\hline Birth weight (g) & 3373 & $3133^{\dagger}$ & $3217^{\dagger}$ & 3470 & 3413 & $3346(487)$ & 2414 \\
\hline Birth length (cm) & 50.5 & $49.5^{\dagger}$ & $49.8^{\dagger}$ & 50.9 & 50.5 & $50.3(2.1)$ & 2382 \\
\hline Head circumference $(\mathrm{cm})$ & 32.9 & $32.3^{\dagger}$ & $32.1^{\dagger}$ & 32.8 & 33.2 & $32.8(1.6)$ & 2397 \\
\hline Ponderal index $\left(\mathrm{kg} / \mathrm{m}^{3}\right)$ & 26.1 & 25.8 & 26.0 & 26.2 & 26.5 & $26.2(2.4)$ & 2382 \\
\hline Gestational age (days) & 285 & 283 & 285 & 287 & 286 & $285(11)$ & 2043 \\
\hline
\end{tabular}


Table 2

Adult Characteristics According to Timing of Prenatal Exposure to the Dutch Famine. (* Geometric Mean and SD)

\begin{tabular}{|c|c|c|c|c|c|c|c|}
\hline & & & & sure to fam & & & \\
\hline & $\begin{array}{l}\text { born } \\
\text { before }\end{array}$ & $\begin{array}{c}\text { late } \\
\text { gestation }\end{array}$ & $\begin{array}{c}\text { mid } \\
\text { gestation }\end{array}$ & $\begin{array}{c}\text { early } \\
\text { gestation }\end{array}$ & $\begin{array}{l}\text { conceived } \\
\text { after }\end{array}$ & all $(S D)$ & $n$ \\
\hline Adult characteristics & & & & & & & \\
\hline Plasma glucose $120 \mathrm{~min} *(\mathrm{mmol} / \mathrm{l})$ & 5.7 & $6.3^{\dagger}$ & 6.1 & 6.1 & 5.9 & $6.0(1.4)$ & 702 \\
\hline Plasma insulin $120 \mathrm{~min} *(\mathrm{pmol} / \mathrm{l})$ & 160 & $200^{+}$ & 190 & 207 & 181 & $181(2.4)$ & 694 \\
\hline IGT/NIDDM (WHO criteria) & $15.0 \%$ & $21.0 \%$ & $14.0 \%$ & $16.0 \%$ & $15.0 \%$ & $16.0 \%$ & 702 \\
\hline Total cholesterol (mmol/l) & 6.06 & 5.83 & 5.80 & 6.13 & 6.00 & $5.97(1.06)$ & 704 \\
\hline HDL cholesterol * $(\mathrm{mmol} / \mathrm{l})$ & 1.35 & 1.32 & 1.37 & $1.26 \dagger$ & 1.32 & $1.33(1.33)$ & 704 \\
\hline LDL cholesterol (mmol/l) & 4.05 & 3.87 & 3.81 & 4.26 & 4.02 & $3.99(1.01)$ & 704 \\
\hline Triglycerides * $(g / l)$ & 1.15 & 1.08 & 1.10 & 1.10 & 1.16 & $1.13(1.71)$ & 704 \\
\hline LDL/HDL cholesterol * & 2.91 & 2.82 & 2.69 & $3.26 \dagger$ & 2.94 & $2.90(1.53)$ & 704 \\
\hline Fibrinogen $(\mathrm{g} / \mathrm{l})$ & 3.02 & 3.05 & 3.05 & 3.21 & 3.10 & $3.07(0.6)$ & 725 \\
\hline Factor VII * (\% of standard) & 128 & 131 & 133 & $117 \dagger$ & 133 & $129(1.4)$ & 725 \\
\hline $\mathrm{BMI}^{*}\left(\mathrm{~kg} / \mathrm{m}^{2}\right)$ & 26.7 & 26.7 & 26.6 & 28.1 & 27.2 & $27.0(1.2)$ & 741 \\
\hline CHD & $3.8 \%$ & $2.5 \%$ & $0.9 \%$ & $8.8 \%^{\dagger}$ & $2.6 \%$ & $3.3 \%$ & 736 \\
\hline Systolic blood pressure $(\mathrm{mmHg})$ & 126.0 & 127.4 & 124.8 & 123.4 & 125.1 & $125.5(15.5)$ & 739 \\
\hline Diastolic blood pressure $(\mathrm{mmHg})$ & 86.2 & 86.4 & 84.4 & 84.8 & 85.2 & $85.6(9.9)$ & 739 \\
\hline Obstructive airways disease & $15.5 \%$ & $15.0 \%$ & $24.8 \%^{\dagger}$ & $23.0 \%$ & $17.3 \%$ & $18.1 \%$ & 733 \\
\hline General health poor & $4.5 \%$ & $6.4 \%$ & $3.7 \%$ & $10.3 \%^{\dagger}$ & $5.3 \%$ & $5.5 \%$ & 912 \\
\hline
\end{tabular}

$\dagger p<0.05$ compared to unexposed

demonstrate an effect of prenatal exposure to famine on blood pressure (Roseboom et al., 1999). A more detailed analysis, however, revealed that blood pressure of the offspring was inversely associated with the protein/carbohydrate ratio of the average ration during the third trimester of pregnancy, whereas it was not associated with any absolute measure of intake during pregnancy (Roseboom et al., 2001). Children whose mothers ate little protein in relation to carbohydrate during the third trimester of pregnancy had higher blood pressures at adult age. This may imply that blood pressure is not so much linked to absolute amounts of nutrients but to variations in the balance of macro-nutrients in the maternal diet during late gestation.

We found that people who had been exposed to famine in mid gestation had an increased prevalence of obstructive airways disease (Lopuhaa et al., 2000). These observations were not paralleled by reduced lung function or increased serum concentrations of $\mathrm{IgE}$. This suggests that the increased prevalence of symptoms and disease may be attributable to increased bronchial reactivity rather than to irreversible airflow obstruction or atopic disease. Because the bronchial tree grows most rapidly in mid gestation, our findings support the hypothesis that fetal undernutrition permanently affects the structure and physiology of the airways during 'critical periods' of development that coincide with periods of rapid growth.

\section{Methodologic Issues}

Our findings mimic a scientific experiment in that they compare the health of people exposed to famine at different times during their gestation. However, the analogy with an experiment is violated to some extent because the famine affected the mother' fertility and the offsprings' survival (Stein et al., 1975). Selective fertility did not seem to explain our findings as adjustments for maternal characteristics that might be proxies for fertility (age, parity, maternal weight and socio-economic status) hardly altered the results. Nor did we find indications that selective early mortality had caused differences in adult health: There were no differences in adult health between people who were born before the famine and those who were conceived after the famine, whereas early mortality differed most strongly between these two groups.

Although the famine was characterised by extreme shortage of food, the availability of food was not the only aspect that varied with the famine. The famine coincided with a very cold winter during which infections were widespread (Burger et al., 1948). Also, the stress experienced by pregnant women during the famine due to lack of food, the war, and the absence of their spouses will have been more extreme than in those who were pregnant before or after the famine. We can not rule out effects of exposure to stress contributing to long-term effects on the offsprings' health. We do not, however, consider stress to be a major cause of the effects we found since we did not find differences in health between people who were born before the famine and those conceived after the famine, whereas one would expect differences in the levels of exposure to stress between these groups. Moreover, we observed effects on health predominantly in the offspring of women exposed to famine in early gestation. One would expect at least the same or even higher levels of stress in pregnant women exposed to famine in late 
or mid gestation, yet, we did not find that offspring of these women had a poorer health. Whatever the true cause of the adaptations made by the fetus that resulted in disease in later life, our findings indicate that an adverse environment in utero can have permanent effects on health.

\section{Conclusion}

Our findings broadly support the hypothesis that chronic diseases originate through adaptations made by the fetus in response to undernutrition. The long-term effects of intrauterine undernutrition, however, depend upon its timing during gestation and on the tissues and systems undergoing critical periods of development at that time. Our findings suggest that risk factors for CHD, such as impaired glucose tolerance, hypercholesterolaemia, raised blood pressure and obesity, which often co-exist, have their origins in utero, but are programmed at different times. Furthermore, our findings suggest that maternal malnutrition during gestation may permanently affect adult health without affecting the size of the baby at birth. This gives the fetal origins hypothesis a new dimension. It may imply that adaptations that enable the fetus to continue to grow may nevertheless have adverse consequences for health in later life. CHD may be viewed as the price paid for successful adaptations to an adverse intra-uterine environment. It also implies that the long-term consequences of improved nutrition of pregnant women will be underestimated if these are solely based on the size of the baby at birth.

We need to know more about what an adequate diet for pregnant women might be. In general, women are especially receptive to advice about diet and lifestyle before and during a pregnancy. This should be exploited to improve the health of future generations.

\section{References}

Banning, C. (1946). Food shortage and public health, first half of 1945. American Academy of Political and Social Sciences, 245, 93-110.

Barker, D. J. P. (1998). Mothers, babies and health in later life (2nd ed.). Edinburgh: Churchill Livingstone.

Burger, G. C. E., Sandstead, H. R., \& Drummond, J. C. (1948). Malnutrition and starvation in Western Netherlands, September 1944 to July 1945: Part I and II. The Hague: General State Printing Office.

Eriksson, J. G., Forsen, T., Tuomilehto, J., Winter, P. D., Osmond,C., \& Barker, D. J. P. (1999). Catch-up growth in childhood and death from coronary heart disease: Longitudinal study. British Medical Journal, 318, 427-431.

Forsen, T., Eriksson, J. G., Tuomilehto, J., Osmond, C., \& Barker, D. J. P. (1999). Growth in utero and during childhood among women who develop coronary heart disease: Longitudinal study. British Medical Journal, 319, 1403-1407.

Huxley, R. R., Shiell, A. W., \& Law, C. M. (2000). The role of size at birth and postnatal catch-up growth in determining systolic blood pressure: A systematic review of the literature. Journal of Hypertension, 18, 815-831.

Leon, D. A., Lithell, H. O., Vågerö, D., Koupilova, I., Mohsen, R., Berglund, L., Lithell, U. B., \& McKeigue, P. M. (1998). Reduced fetal growth rate and increased risk of death from ischaemic heart disease: Cohort study of 15000 Swedish men and women born 1915-1929. British Medical Journal, $317,241-245$.

Lithell, H. O., McKeigue, P. M., Berglund, L., Mohsen, R., Lithell, U. B., \& Leon, D. A. (1996). Relation of size at birth to noninsulin dependent diabetes and insulin concentrations in men aged 50-60 years. British Medical Journal, 312, 406-410.

Lopuhaa, C. E., Roseboom, T. J., Osmond, C., Barker, D. J. P., Ravelli, A. C. J., Bleker, O. P., van der Zee, J. S., \& van der Meulen, J. H. P. (2000). Atopy, lung function and obstructive airways disease in adults after prenatal exposure to the Dutch famine. Thorax, 55, 555-561.

Michels, K. B., Trichopoulos, D., Robins, J. M., Rosner, B. A., Manson, J. E., Hunter, D. J., Colditz, G. A., Hankinson, S. E., Speizer, F. E., \& Willett, W. C. (1996). Birth weight as a risk factor for breast cancer. Lancet, 348, 1542-1546.

Murray, J. C. L., \& Lopez, A. D. (1994). Global and regional cause-of-death patterns in 1990. In C. J. L. Murray \& A. D. Lopez (Eds.), Global comparative assessments in the health sector. Disease burden, expenditures, and intervention packages (pp. 21-54). Geneva: World Health Organisation.

Osmond, C., Barker, D. J. P., Winter, P. D., Fall, C. H. D., \& Simmonds, S. J. (1993). Early growth and death from cardiovascular disease. British Medical Journal, 307, 1519-1524.

Rich-Edwards, J. W., Stampfer, M. J., Manson, J. E., Rosner, B., Hankinson, S. E., Colditz, G. A., Willet, W. C., \& Hennekes, C. H. (1997). Birth weight and risk of cardiovascular disease in a cohort of men followed up since 1976. British Medical Journal, 315, 396-400.

Ravelli, A. C. J., van der Meulen, J. H. P., Michels, R. P. J., Osmond, C., Barker, D. J. P., Hales, C. N., \& Bleker, O. P. (1998). Glucose tolerance in adults after prenatal exposure to the Dutch famine. Lancet, 351, 173-177.

Ravelli, A. C. J., van der Meulen, J. H. P., Osmond, C., Barker, D. J. P., \& Bleker, O. P. (1999). Obesity in adults after prenatal exposure to famine. American Journal of Clinical Nutrition, 70, $811-816$

Roseboom, T. J., van der Meulen, J. H. P., Osmond, C., Barker, D. J. P., Ravelli, A. C. J., \& Bleker, O. P. (2001). Adult survival after prenatal exposure to the Dutch famine 1944-45. Pediatric and Perinatal Epidemiology, 15, 220-225.

Roseboom, T. J., van der Meulen, J. H. P., Osmond, C., Barker, D. J. P., Ravelli, A. C. J., \& Bleker, O. P. (2000). Plasma lipid profile after prenatal exposure to the Dutch famine. American Journal of Clinical Nutrition, 72, 1101-1106.

Roseboom, T. J., van der Meulen, J. H. P., Ravelli, A. C. J., Osmond, C., Barker, D. J. P., \& Bleker, O. P. (2000). Plasma fibrinogen and factor VII concentrations in adults after prenatal exposure to the Dutch famine. British Journal of Haematology, 111, 112-117. 
Roseboom, T. J., van der Meulen, J. H. P., Osmond, C., Barker, D. J. P., Ravelli, A. C. J., Schroeder-Tanka, J. M., van Montfrans, G. A., Michels, R. P. J., \& Bleker, O. P. (2000). Coronary heart disease in adults after prenatal exposure to the Dutch famine. Heart, 84, 595-598.

Roseboom, T. J., van der Meulen, J. H. P., Ravelli, A. C. J., van Montfrans, G. A., Osmond, C., Barker, D. J. P., \& Bleker, O. P. (1999). Blood pressure in adults after prenatal exposure to famine. Journal of Hypertension, 17, 325-330.

Roseboom, T. J., van der Meulen, J. H. P., van Montfrans, G. A., Ravelli, A. C. J., Osmond, C., Barker, D. J. P., \& Bleker, O. P.
(2001). Maternal nutrition during gestation and adult blood pressure. Journal of Hypertension, 19, 29-34.

Stein, C. E., Fall, C. H. D., Kumaran, K., Osmond, C., Cox, V., \& Barker, D. J. P. (1996). Fetal growth and coronary heart disease in South India. Lancet, 348, 1269-1273.

Stein, Z. A., Susser, M., Saenger, G., \& Moraolla, F. (1975). Famine and Human development: The Dutch Hunger Winter of 1944-45. New York, Oxford University Press.

Trienekens, G. (1985). Tussen ons volk en de honger (1st ed.). Utrecht, Matrijs.

\section{Call for papers}

This issue of Twin Research, to be published in 2002, will include the proceedings of the symposium on The Loss of a Twin held at the $10^{\text {th }}$ International Congress on Twin Studies in July 200I.

In addition we will welcome original papers, reviews, case histories and brief 'personal experiences'. Although primarily concerned with bereavement following death, papers on the loss of the twinship through disability or separation will also be considered.

Papers should be submitted to the Guest Editors of the Special Issue, Elizabeth Bryan and Ronald Higgins (ebryan@higgins7.co.uk), as soon as possible.
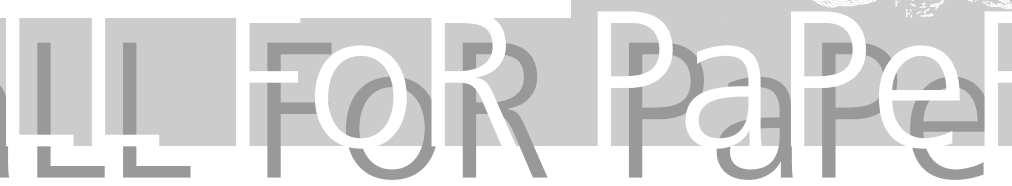

Twin Research October 2001 